\title{
Gestão do conhecimento em empresas de consultoria ambiental
}

\author{
Bruno Pontes Costanzo ${ }^{\mathrm{a}}$, Luis Enrique Sánchez ${ }^{\mathrm{b} *}$ \\ abrunopc@usp.br, Poli/USP, Brasil \\ b*lsanchez@usp.br, Poli/USP, Brasil
}

\begin{abstract}
Resumo
Visando explorar como as empresas de consultoria especializadas em avaliação de impacto ambiental promovem gestão do conhecimento, foram levantadas práticas adotadas por oito empresas desse ramo. 0 estudo procurou verificar se há relação entre a classificação das empresas segundo o grau de complexidade e a inovação em sua carteira de projetos, com práticas e ferramentas de gestão do conhecimento mencionadas na literatura, com os repositórios internos de conhecimento e com suas experiências relacionadas à criação, troca e retenção de conhecimento. Foram feitas entrevistas qualitativas com integrantes chave dessas organizações. Constatou-se que práticas de socialização do conhecimento são usadas pela maioria das consultorias, mas nenhuma delas, ao concluir um projeto, realiza uma avaliação crítica que possibilite captar as lições aprendidas. Rotinas e procedimentos para transformação de conhecimento tácito em explícito são pouco utilizadas, assim como métodos de combinação de conhecimento. Conclui-se que o nível de diversificação da atuação das consultorias, em relação a mercados e territórios, pode indicar as ferramentas mais apropriadas para essas organizações.
\end{abstract}

Palavras-chave

Gestão do conhecimento. Empresas de consultoria. Repositórios de conhecimento. Estudos de impactos ambientais.

\section{Introdução}

Consultoria ambiental é uma atividade especializada de prestação de serviços, caracterizada pelo uso intensivo de conhecimento. Dentre as diversas modalidades de serviços características desse ramo, a avaliação de impacto ambiental (AIA) de projetos é uma das mais bem estabelecidas. A preparação de um estudo de impacto ambiental (ElA) como requisito para aprovação de projetos que tenham o potencial de causar significativa degradação ambiental é uma exigência legal em inúmeros países. Tais estudos, elaborados por equipes multidisciplinares, produzem e compilam grande quantidade de informação sobre 0 meio ambiente e o projeto analisado e são submetidos à aprovação de um órgão governamental competente, sendo também submetidos à consulta pública (Sánchez, 2006).

0 grupo de empresas de consultoria que realizam esses estudos inclui desde pequenas empresas de atuação local até corporações multinacionais com escritórios em vários países. Assim como outras especializações de consultoria, tais empresas podem estar na vanguarda do desenvolvimento de práticas relativas à gestão do conhecimento (GC) (Käpylä et al., 2011; Starbuck, 1992) e interagem com organizações governamentais que também dispõem de equipes multidisciplinares e são intensivas em conhecimento (Bond et al., 2010; Sánchez \& Morrison-Saunders, 2011).

Embora o ramo de consultoria ambiental seja hoje em dia bastante diversificado e segmentado, atendendo a diferentes necessidades dos clientes e empregando diversas ferramentas (Sánchez, 2010), o grupo de empresas envolvido na preparação de ElAs foi escolhido para este estudo por ser bem consolidado - abrangendo empresas contando até 27 anos de atuação no mercado brasileiro - e diversificado -, com empresas de diferentes portes e, supostamente, distinta capacidade gerencial. Além da 
necessidade de integração entre disciplinas, os EIAs necessitam também de integração de especialistas internos e externos às firmas de consultoria. Portanto, supõe-se que as empresas adotem rotinas e ferramentas e possuam um ambiente que motive e facilite a troca de informações e conhecimentos no âmbito da equipe técnica envolvida nos estudos ambientais.

Outro aspecto significativo é a existência de diversas partes envolvidas no processo de AlA, incluindo órgãos públicos e sociedade civil, que influenciam o trabalho desenvolvido pela empresa de consultoria. As empresas de consultoria ambiental desempenham um papel duplo: são tanto usuárias como fornecedoras de informação e conhecimento durante o desenvolvimento dos estudos ambientais. Fitzpatrick (2006) mostrou fortes evidências e analisou o aprendizado dos participantes nas audiências públicas, que são obrigatoriamente parte do processo de AIA no Canadá, ao passo que Sinclair et al. (2008) reviram o papel do processo de AIA para fomentar a aprendizagem social, também naquele país.

Este trabalho trata somente da troca de informação e conhecimento dentro de empresas de consultoria. Rueschemeyer (1983), tratando principalmente dos colaboradores dessas empresas, propõe que consultores são indivíduos que possuem competências específicas e desenvolvem relações informais para trocar conhecimento. Taminiau et al. (2009) defendem que o caminho mais frutífero para a inovação em empresas de consultoria é o da transferência informal interna de conhecimento. Hanisch et al. (2009) sugerem que o potencial da $\mathrm{GC}$ em ambientes de projetos é especialmente alto para empresas intensivas em conhecimento, tal como as consultorias.

A motivação para o desenvolvimento deste estudo reside na premissa de que a GC é ação estratégica central e competência fundamental das empresas de consultoria (Nakano, 2002). No fato de que os ElAs são multidisciplinares, com diversas partes envolvidas, reside a expectativa de se encontrar ambiente no qual se dê grande valor à troca de informação e conhecimento. Observando-se que na literatura internacional não foram identificados trabalhos com esse enfoque, espera-se identificar processos, ferramentas e práticas de GC utilizadas por essas consultorias.

A possibilidade de descrever as boas práticas dessas empresas, empregadas de forma planejada ou casual em seu cotidiano de trabalho, resulta em uma motivação ainda mais expressiva: contribuir para a discussão da GC nas consultorias ambientais e, indiretamente, para a melhoria da qualidade dos estudos por elas desenvolvidos, uma vez que a qualidade do trabalho de uma equipe multidisciplinar não reside somente na experiência de seus membros mas, sobretudo, no sinergismo de suas interações (André et al., 2003).

\section{Objetivos}

0 objetivo deste estudo é explorar como as empresas de consultoria ambiental promovem a GC. Para tanto, procurou-se verificar se há relação entre a classificação das empresas no contínuo de Maister (1997) com: (i) as práticas e ferramentas propostas por Silva (2004), fundamentadas, por sua vez, no ciclo de aprendizado de Nonaka \& Takeuchi (1995); (ii) os repositórios de conhecimento utilizados pelas empresas; e (iii) suas experiências relacionadas à criação, troca e retenção de conhecimento. 0 estudo também tencionou: (iv) verificar se as relações informais dos consultores para a troca conhecimento (Rueschemeyer, 1983) se aplicam às consultorias ambientais e se dependem de sua classificação no contínuo de Maister; e (v) identificar os processos, ferramentas e práticas utilizados pelas empresas para incentivar a socialização e se esse esforço pode estar relacionado com a classificação de seus projetos no contínuo de Maister.

A Figura 1 ilustra o objetivo do estudo, cujo referencial teórico é discutido na seção 4.

A proposição do estudo é que as empresas de consultoria ambiental que tiveram destaque em relação ao número de ElAs protocolados nos órgãos licenciadores (arbitrado, para fins deste estudo, em pelo menos 10 ElAs nos últimos 10 anos) adotam práticas e ferramentas bem estruturadas que incluem a GC. Serão explorados o como e o porque de essas empresas orientarem esforços, ou não, para estabelecimento de um ambiente mais propício à criação, troca e retenção de conhecimento.

Neste trabalho, pretende-se abordar os quatro níveis de aprendizagem (individual, grupal, organizacional e interorganizacional), procurando identificar eventos internos e externos às empresas que estimulem aprendizagem. Portanto, além da análise de como essas empresas criam conhecimento através de suas rotinas, práticas e processos internos, explora-se como aprendem ao se deparar com situações externas, como audiências públicas, contato com órgãos ambientais, empreendedores e comunidades envolvidos no licenciamento.

\section{Referencial teórico}

\subsection{Elaboração de um Estudo de Impacto Ambiental}

O ElA é um estudo técnico "[...] que examina as consequências ambientais futuras de uma ação proposta [...]" (Sánchez, 2006, p. 39), sendo legalmente exigivel para projetos que tenham o potencial de 
Contínuo de Maister (1997)
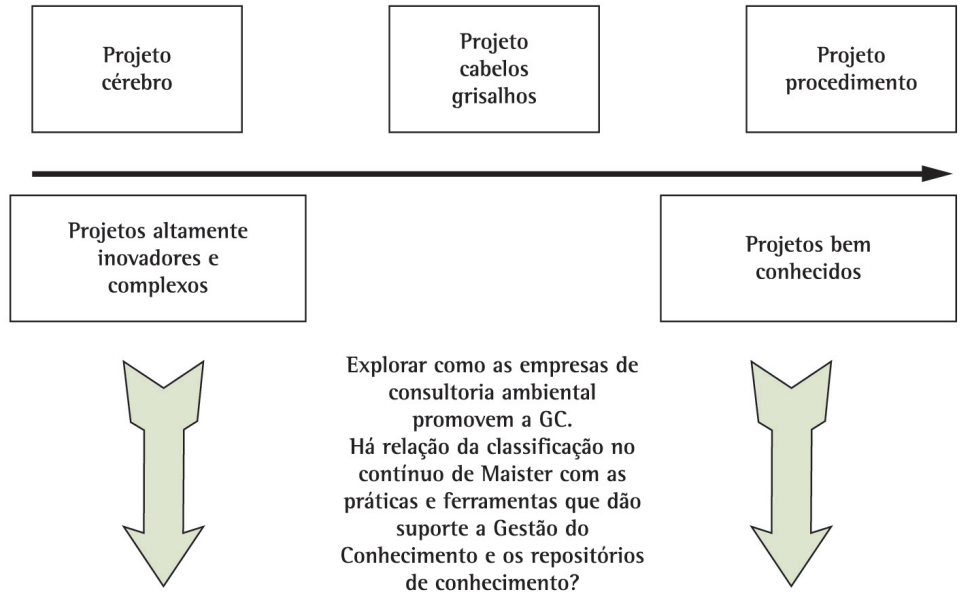

Explorar como as empresas de consultoria ambiental promovem a GC.

Há relação da classificação no contínuo de Maister com as práticas e ferramentas que dão suporte a Gestão do

Conhecimento e os repositórios de conhecimento?

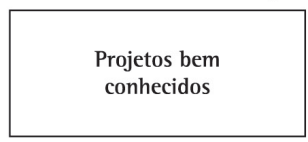

Repositórios de conhecimento (Walsh \& Ungson, 1991, Olivera, 2000; Nakano \& Fleury (2005), Child \& Shumate (2007))

Figura 1. Representação gráfica do objetivo do estudo.

causar significativo impacto ambiental. 0 ElA deve considerar os impactos de projetos sobre os meios físico, biótico e socioeconômico, sob uma perspectiva multi e interdisciplinar (André et al., 2003).

Para fins desta pesquisa, o processo de desenvolvimento do EIA é composto por seis macroetapas (Figura 2). Quando uma empresa de consultoria é convidada ou decide participar de uma licitação para elaborar um EIA, prepara uma proposta técnico-comercial com base em (1) informações técnicas sobre o projeto fornecidas pelo empreendedor; e (2) seu conhecimento do tipo de empreendimento e, eventualmente, da região ou do local pretendido para implantação. No estado de São Paulo é necessário preparar um documento denominado Plano de Trabalho, que contém as diretrizes a serem seguidas para a preparação do ElA.

\subsection{Empresas de serviços profissionais}

As consultorias ambientais se classificam como empresas de serviços profissionais, ou seja, organizações que empregam profissionais na prestação de seus serviços (Nakano, 2002). Tais empresas possuem duas características básicas: alto grau de personalização e alto grau de contato pessoal em seus serviços
(Slack et al., 1997). Segundo Nakano (2002), as empresas de serviços profissionais possuem alternativas de estratégias de mercado bem definidas, conforme apresentado no trabalho de Maister (1997).

O contínuo de Maister (1997) servirá como referência para a compreensão do nível de customização e inovação dos projetos de licenciamento ambiental desenvolvidos pelas consultorias. Esse teórico define três necessidades básicas de mercado, exemplificando-as com três projetos fictícios, que chamou de: "cérebro", “cabelos grisalhos” e "procedimento" (Figura 3).

Maister (1997) cita que o apelo comercial de empresas voltadas para projetos "cérebro" seria "Contratemos, pois somos mais inteligentes", para empresas focadas em projetos "cabelos grisalhos" seria "Contratemos, pois já passamos por essa situação antes”. Finalmente, para empresas voltadas para projetos "procedimento" seria "Contratemos, pois sabemos como fazer isso e podemos entregá-lo efetivamente".

\subsection{Gestão do conhecimento e aprendizagem organizacional}

Dentre as inúmeras conceituações de gestão do conhecimento, a proposição de Nonaka \& Takeuchi 

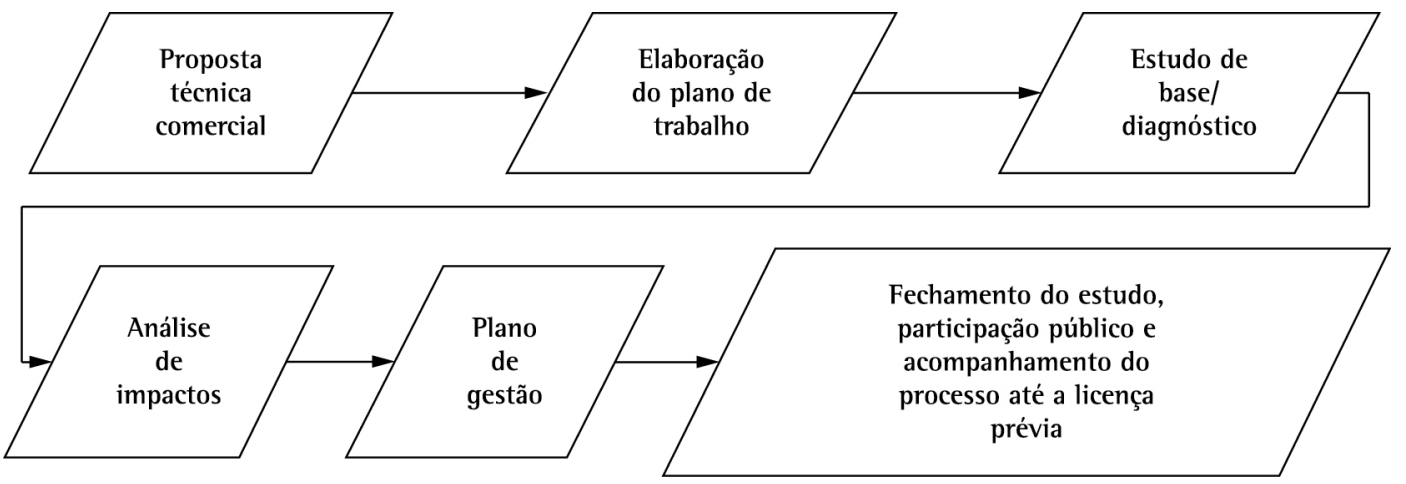

Figura 2. Macroetapas do processo de desenvolvimento de ElAs.
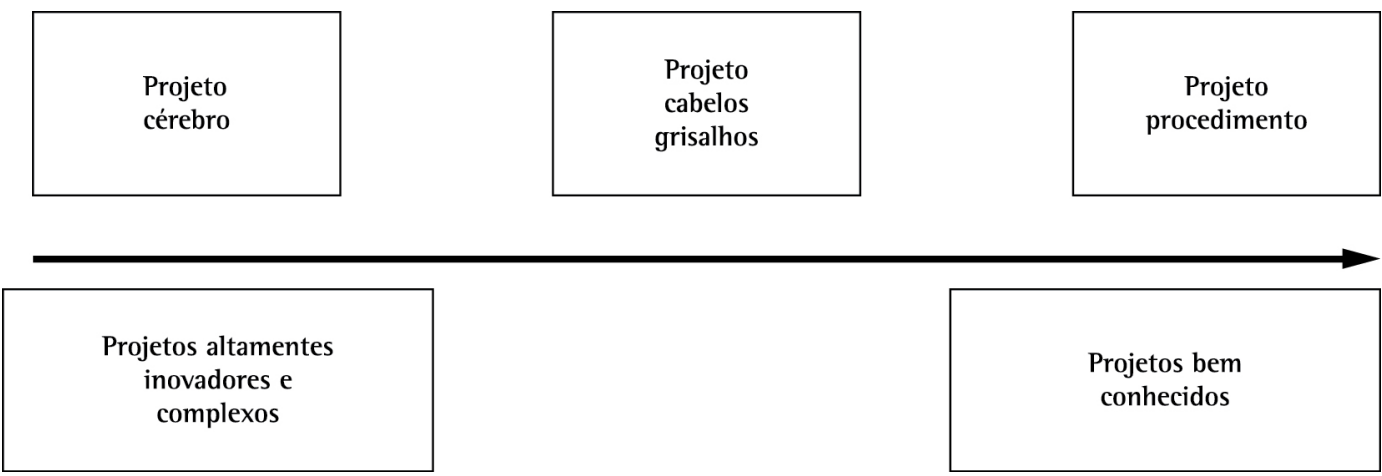

Figura 3. Contínuo de Maister (1997).

(1995) é adequada ao objetivo deste trabalho. Esses autores definem GC como o emprego de princípios, estratégias, políticas, processos e estruturas que visam estimular as pessoas a criar, buscar, preservar, valorizar e compartilhar novas interpretações (crenças) sobre a realidade em que trabalham.

Diversos teóricos já exploraram os níveis em que o conhecimento pode ocorrer, Nonaka \& Takeuchi (1995), assim como Crossan et al. (1999), consideram que existem diferentes possibilidades para a dimensão ontológica do conhecimento: individual, grupal, organizacional e interorganizacional, e que esses diferentes níveis estão interligados por processos sociais. Crossan et al. (1999) ainda enfatizam que o uso de diferentes níveis de análise é uma das características da literatura sobre GC. Schulz (2001) argumenta que as pesquisas sobre conhecimento organizacional em geral focalizam os processos de criação e disseminação dentro de uma organização ou entre várias delas.

A literatura assume que a GC em uma organização facilita a aprendizagem, um processo que pode ocorrer nos níveis individual, grupal e organizacional (Antonello, 2005). Para muitos autores, a aprendizagem é associada necessariamente a mudança (Argyris \& Schön, 1996; Antonello, 2005). Já a aprendizagem organizacional é um processo de aquisição, retenção e mudança através de ações coletivas (Cook \& Yanow, 1993).

Fiol \& Lyles (1985) argumentam que, na área de aprendizagem organizacional, três pontos de consenso existem: (1) a relevância do alinhamento ao ambiente, (2) a distinção entre aprendizagem organizacional e individual; (3) a presença de quatro fatores contextuais chave (cultura, estratégia, estrutura e ambiente). Para essas autoras, a aprendizagem também implica mudança, comportamental ou cognitiva. A aprendizagem simples, ou de baixo nível, ocorre quando a mudança de comportamento não está associada a uma mudança cognitiva, Argyris \& Schön (1996) classificam esse tipo de aprendizagem como aprendizagem de ciclo simples. A aprendizagem de alto nível, segundo Fiol \& Lyles (1985), corresponde a um processo de caráter cognitivo que pode implicar também mudança de comportamento e apresenta resultados mais impactantes e duradouros em toda organização.

Argyris \& Schön (1996) consideram que a aprendizagem diz respeito ao processo eficaz e a interpretações (e respostas) às informações internas e externas, ou seja, a organização aprende se o seu comportamento muda frente ao processamento de 
informações. Esses autores propõem os ciclos de aprendizagem conforme apresentados na Figura 4. Propõe-se, no presente estudo, que possa haver uma relação entre o contínuo de Maister (1997) e os ciclos de aprendizagem de Argyris \& Schön (1996), sendo que quanto mais as empresas tendem para uma atuação em projetos "cérebro", mais ciclos duplos e dêuteros de aprendizagem ocorrerão.

\subsubsection{Criação do conhecimento: práticas e ferramentas}

Para o estudo das práticas e ferramentas de GC utilizadas pelas empresas, adota-se a classificação bastante difundida de conhecimento tácito e explícito. Nonaka \& Takeuchi (1995) definem quatro modos de conversão dos dois formatos de conhecimento: socialização, externalização, combinação e internalização. Silva (2004) propõe práticas para auxiliar as conversões de conhecimento, ao passo que Lethbridge (1998) usa parâmetros de capacidade da organização para realizar a GC, a saber:

- Parâmetros organizacionais: como disseminação de trabalho em equipes; rotatividade entre diferentes postos de trabalho; procedimentos de gestão da qualidade que motivem a comunicação e o trabalho em equipe;

- Parâmetros de recursos humanos: como programas de treinamento e desenvolvimento; promoção de atividades internas enfocando a troca de experiências adquiridas nos projetos;

- Parâmetros de sistemas de informação: como tecnologias que permitam armazenar e recuperar informações ou que facilitem a comunicação.

As Figuras 5, 6, 7 e 8 sumarizam os modos de conversão de conhecimentos e as práticas e ferramentas que a auxiliam, ao lado de proposições sobre os relacionamentos entre os modos de conversão e

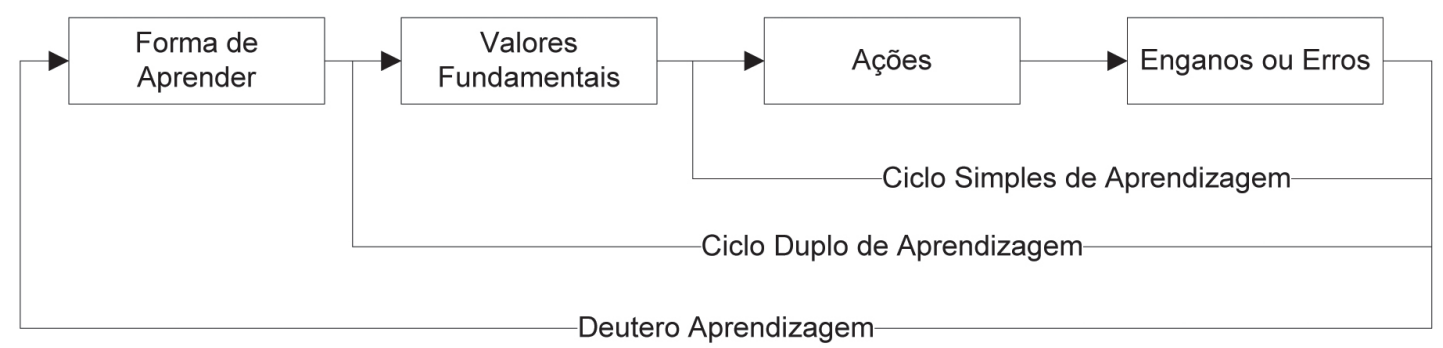

Figura 4. Ciclos de aprendizagem - Argyris \& Schön (1996).

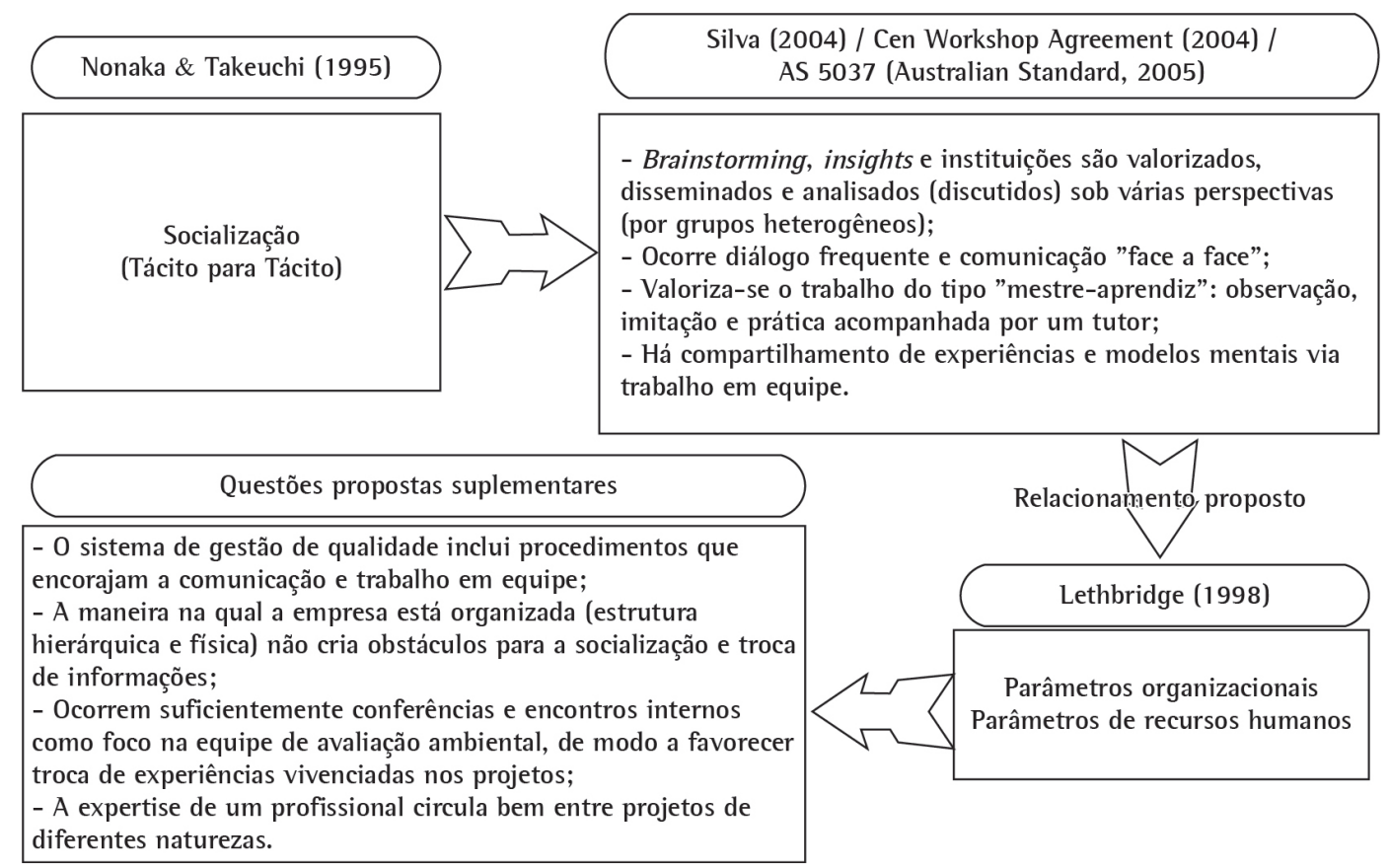

Figura 5. Questões sobre socialização. 


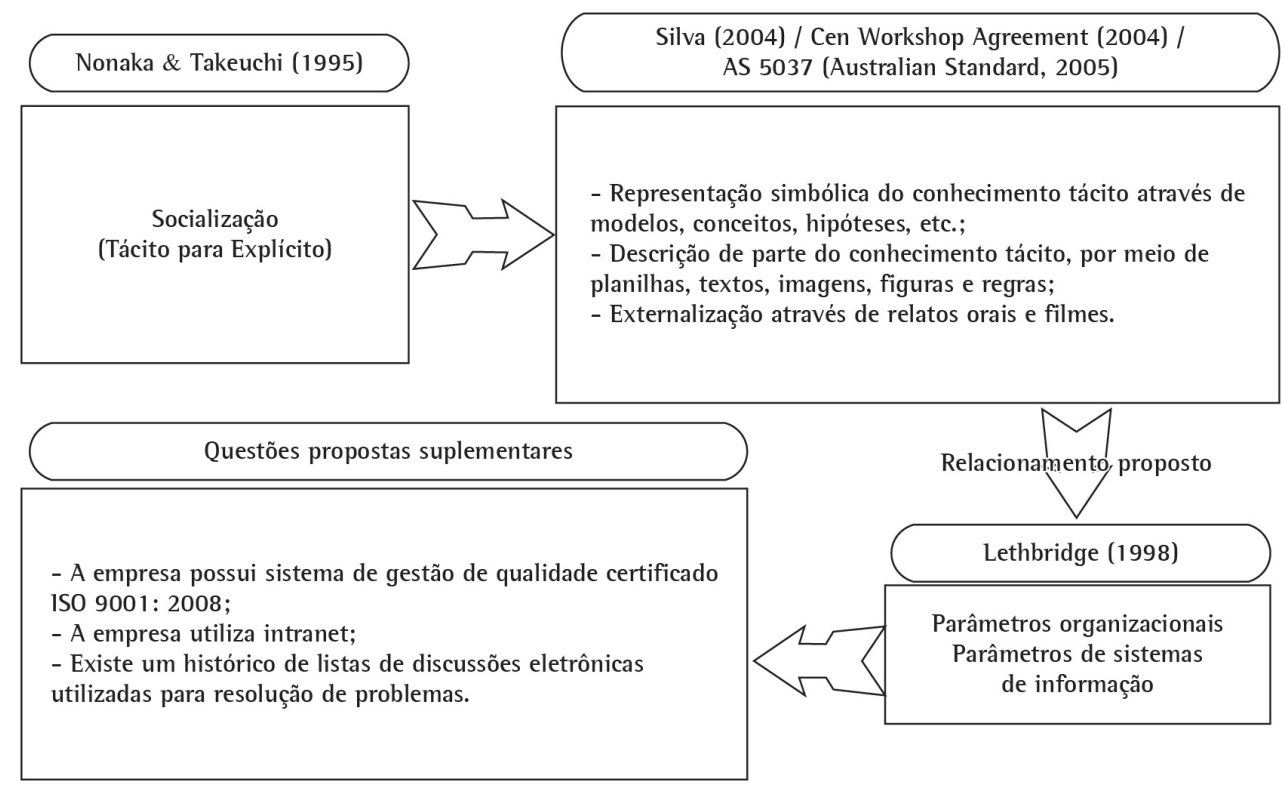

Figura 6. Questões sobre externalização.

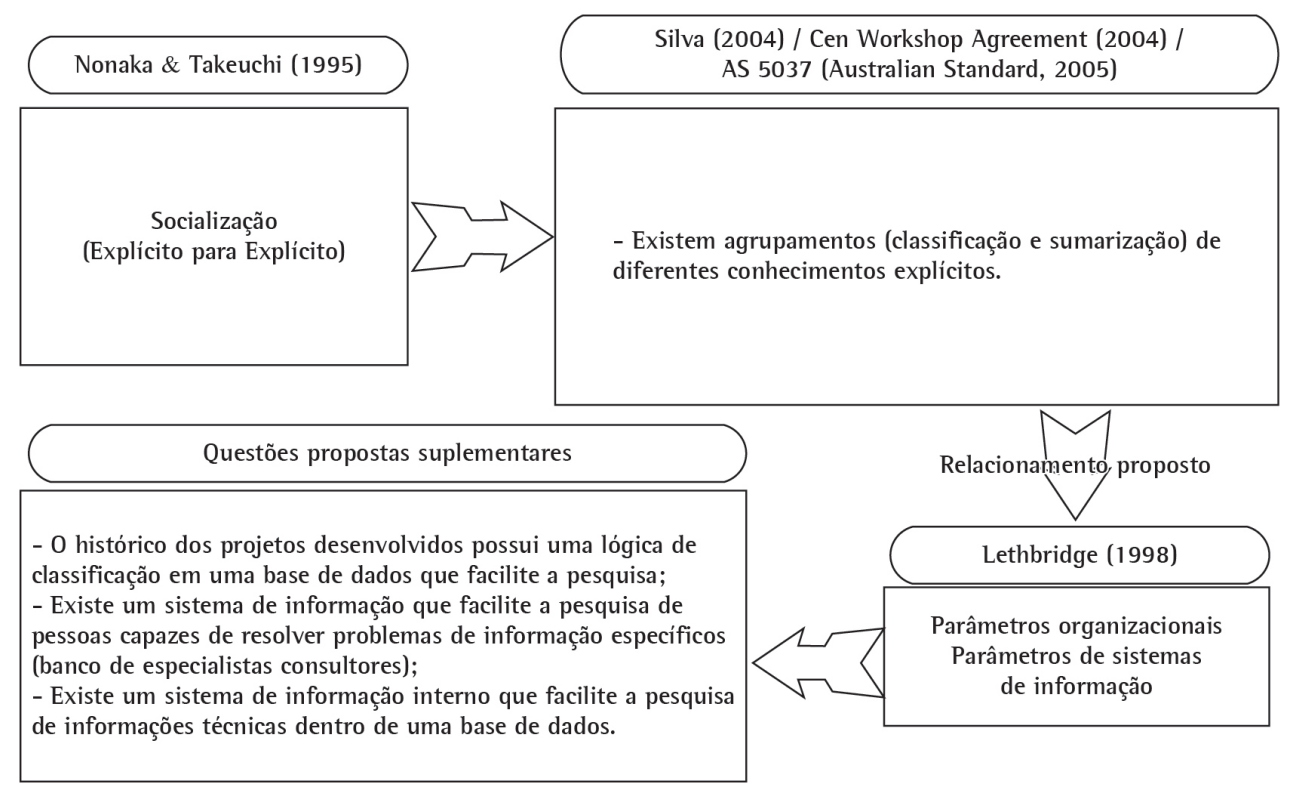

Figura 7. Questões sobre combinação.

os parâmetros de capacidade da organização e de questões suplementares. Esses esquemas nortearam esta pesquisa e relacionam-se com o conteúdo do questionário adotado (seção 4), especificamente das colunas 3, 4 e 5 do Tabela 1.

\subsubsection{Memória organizacional: repositórios de conhecimento}

Estoques de conhecimentos resultam de aprendizagem e desempenham papel fundamental na manutenção e aprimoramento da capacidade competitiva de uma organização (Nakano \& Fleury, 2005). Este estudo procurou identificar os repositórios de conhecimento adotados pelas empresas, considerando que a memória organizacional é composta por um conjunto de diferentes locais de armazenamento. Walsh \& Ungson (1991) definem cinco repositórios de conhecimento: os indivíduos, a cultura organizacional, as transformações (procedimentos operacionais, por exemplo), a estrutura hierárquica e o ambiente (instalações físicas). Outros autores 


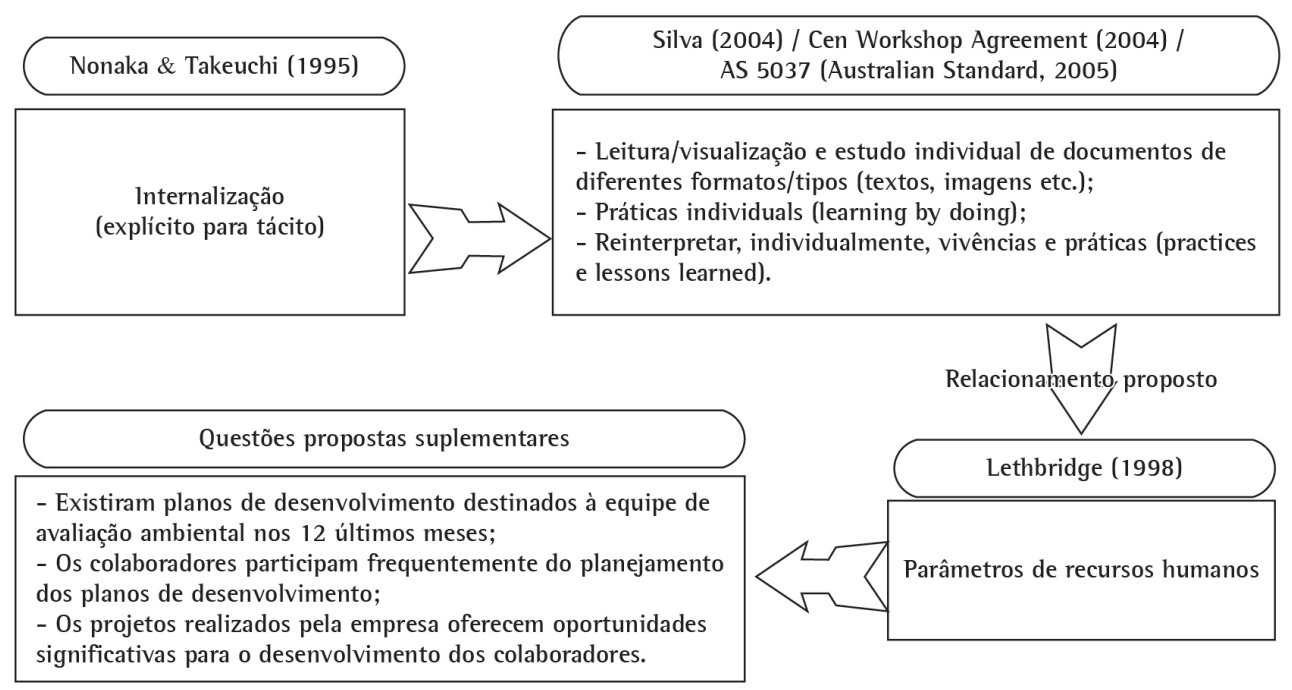

Figura 8. Questões sobre internalização.

definem repositórios de maneira diferente. Olivera (2000), que estudou uma empresa de consultoria empresarial de grande porte, propõe os seguintes sistemas de armazenamento: redes de relacionamento interpessoal, centros de conhecimento, bancos de dados e listas de discussão eletrônica. Esse mesmo autor define centros de conhecimento como grupos formais de especialistas que coletam e fornecem informações sobre a experiência da organização acerca de um domínio específico. Hansen et al. (1999), também fundamentados em observações a empresas de consultoria, propõem que as organizações enfatizam o uso de redes de relacionamento ou bancos de dados eletrônicos conforme suas estratégias de mercado, ou seja, em empresas classificadas na região de projetos "procedimento" no contínuo de Maister (1997), o uso de banco de dados seria o estoque de conhecimento predominante, enquanto as empresas classificadas em projetos "cérebro" utilizariam com mais intensidade as redes de relacionamento.

Daft \& Lengel (1986) propõem que a informação auxilia as organizações a lidarem com incerteza e ambiguidade. Galbraith (1973) define incerteza como a diferença entre a quantidade de informação necessária para a execução de uma tarefa e a quantidade de informação que se possui. Nessa visão, a solução para a incerteza seria a reunião de maior quantidade de informações relevantes. Daft \& Lengel (1986) definem ambiguidade como múltiplas interpretações conflitantes sobre uma determinada situação e consideram que para solucionar ambiguidades os membros da organização precisam interagir e chegar a uma interpretação compartilhada.

Considera-se que quanto mais as empresas tendem para uma atuação em projetos “cérebro", mais elas possuirão situações ambíguas; se tenderem a projetos "procedimento" tenderão também a enfrentar situações de incerteza com maior frequência.

\section{Metodologia}

A pesquisa utilizou entrevistas qualitativas para coleta de informação e evidências (Eisenhardt, 1989; Yin, 2001; Voss et al., 2002; Miguel, 2007). Dadas as características do universo relativamente pequeno de empresas de consultoria que atuam na área de estudo, a amostragem foi intencional, selecionando amostras (ou seja, empresas) por motivos teóricos. Assim, procurou-se identificar empresas de pequeno a grande porte e desde as mais antigas até as mais recentes.

Para a seleção do número de entrevistas qualitativas, utilizou-se a ideia de saturação apresentada por Eisenhardt (1989), onde o pesquisador percebe que o número de casos é adequado quando, ao adicionar mais um, não se registram ganhos teóricos na pesquisa. Yin (2001), alinhado com a ideia de saturação, cita que o número de casos deve ser suficiente para encontrar algum padrão de resultados que forneça base substancial para a proposição inicial. Para a seleção das consultorias ambientais pesquisadas, o estudo foi limitado àquelas sediadas no estado de São Paulo, tendo sido identificadas empresas que protocolizaram maior número de ElAs, segundo lista fornecida pela Secretaria de Meio Ambiente do Estado de São Paulo.

Em sua maioria, são empresas de constituição relativamente recente (de 5 a 27 anos de existência, no momento de coleta de dados, em 2011), com 


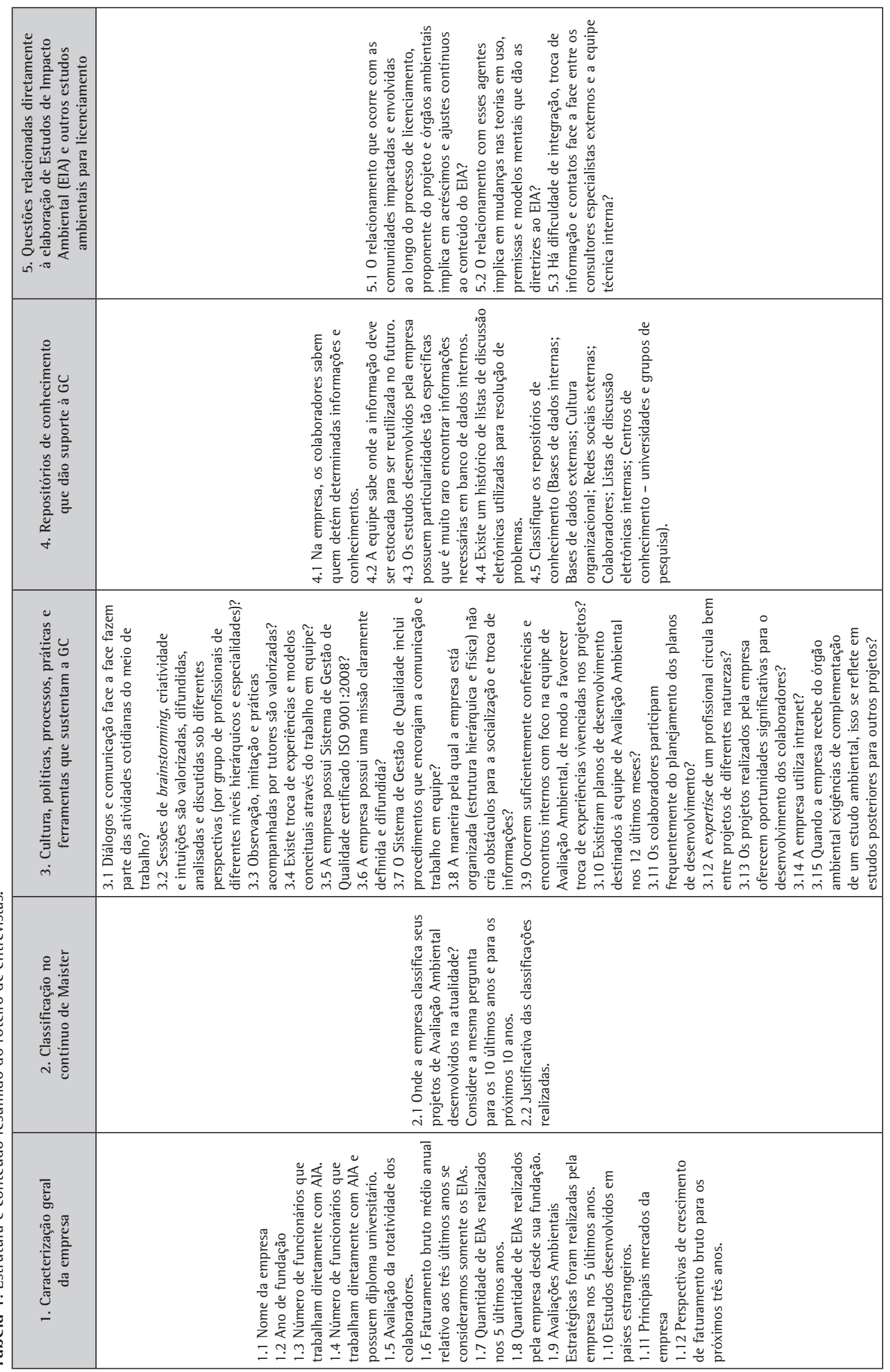


equipes de 1 a 80 colaboradores e que lançam mão de consultores externos. 0 mercado de consultoria ambiental é bastante segmentado, contando com empresas atuantes em diversos nichos, segundo sua especialização. Este estudo trata somente das empresas que elaboram ElAs completos.

Um roteiro semiestruturado de entrevistas foi preparado e testado em quatro empresas. Após essa aplicação piloto, o roteiro foi modificado, assumindo o conteúdo resumido no Tabela 1. As entrevistas foram gravadas e transcritas (com exceção da primeira) imediatamente após sua realização. Para aquela que não foi gravada, notas foram tomadas por dois entrevistadores. Para facilitar a análise do conteúdo transcrito, conforme proposto por Miguel (2007), foi realizado um resumo com os principais temas abordados em cada transcrição (redução dos dados) e posteriormente foram identificadas as semelhanças, contrastes e relação de opiniões entre as declarações dos entrevistados.

\section{Resultados obtidos}

Nesta seção são apresentados os resultados das entrevistas. Foram estudadas oito empresas e realizadas $21 \mathrm{~h} 03$ min de entrevistas, sendo que $17 \mathrm{~h} 24 \mathrm{~min}$ foram gravadas. As entrevistas foram agendadas previamente, por telefone. Todas as empresas convidadas aceitaram participar da pesquisa. 0 roteiro foi enviado previamente aos entrevistados, apresentados no Tabela 2. Coletivamente, as empresas que integram a amostra já elaboraram 299 estudos de impacto ambiental.

\subsection{Perfil das empresas estudadas}

As oito empresas estudadas foram: Mineral Engenharia e Meio Ambiente; CPEA - Consultoria, Planejamento e Estudos Ambientais; JGP Gestão Ambiental; Arcadis Tetraplan; TN Ambiental; ERM - Environmental Resources Management; D-Freire Consultoria Ambiental; e Prominer Projetos. Para que os resultados do estudo não sejam correlacionados diretamente às empresas, atribuíram-se códigos aleatoriamente (A, B, C, D, E, F, G e H) a cada empresa. 0 Tabela 2 apresenta algumas características dessas empresas.

\subsection{Classificação no contínuo de Maister}

Os representantes das empresas entrevistadas classificaram a carteira de seus projetos, relativos à AlA, no contínuo de Meister (1997). A classificação considerou os projetos realizados no passado, em

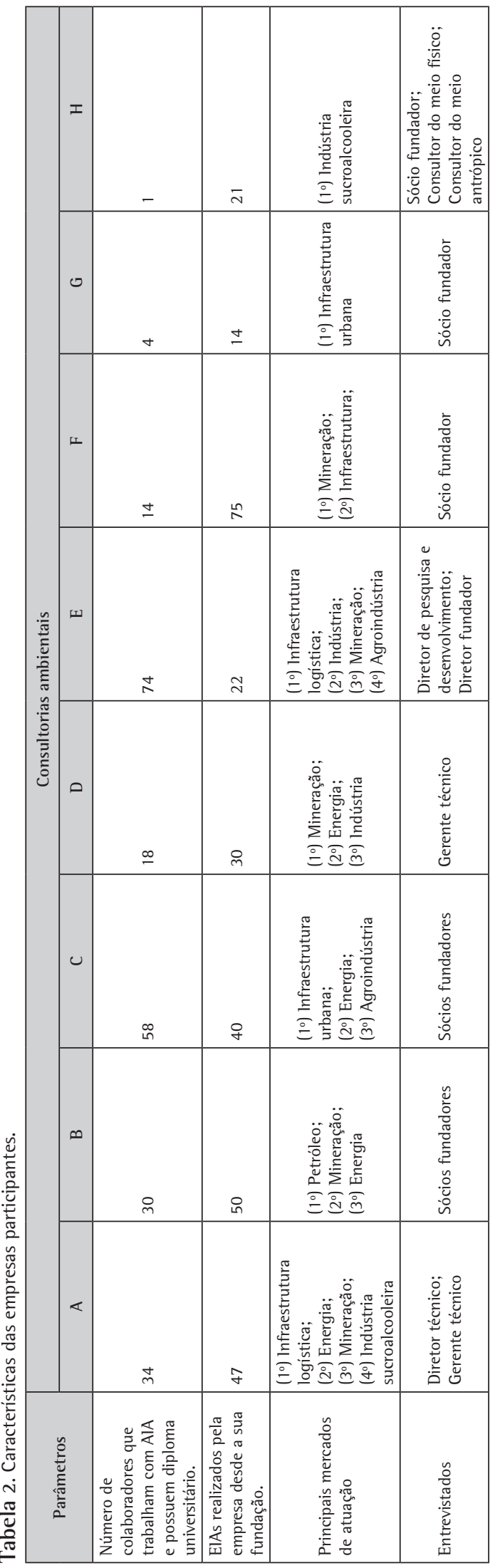


realização e previstos para o futuro. Nota-se, no Tabela 3, que apenas uma consultoria (A) manteve sua classificação constante no intervalo temporal definido; três empresas (B, D e G) opinaram que seus serviços de avaliação ambiental evoluem no tempo de situações menos para mais complexas, que requerem inovação, e quatro empresas (C, E, F e H) opinaram que a carteira de seus projetos tende a se simplificar com o passar do tempo.

A empresa A considera que a proporção 60\%, 35\% e $5 \%$ em projetos "procedimento", "cabelos grisalhos" e "cérebro", respectivamente, é ideal para sua cultura e seus objetivos. Os entrevistados argumentaram que a participação em projetos que necessitam de soluções inovadoras é essencial para estimular sua equipe sênior e reconstruir continuamente suas competências, enquanto que sua relevante atuação em projetos "procedimento" possibilita a manutenção e desenvolvimento da equipe júnior, além de contribuir para o equilíbrio financeiro.

Dentre as empresas que se classificaram em evolução para carteiras de projetos mais complexos e inovadores, a empresa B argumentou que a evolução tecnológica dos empreendimentos, associada às particularidades ambientais dos territórios onde os projetos propostos se localizam, resulta em grande probabilidade de existência de cenários complexos para AlA e que a empresa busca atuar nesses contextos. A empresa $D$ citou quatro argumentos que justificam essa evolução: (i) aumento da complexidade do uso e ocupação do território; (ii) aumento do rigor dos órgãos públicos; (iii) crescimento da participação pública; (iv) sensibilização dos clientes sobre temas ambientais. A empresa G citou experiências em projetos portuários e planos urbanísticos que necessitaram de soluções inovadoras desenvolvidas entre consultor ambiental, empreendedor e grupos sociais impactados. Comentou também seu anseio em aumentar sua participação em projetos com essas características.

No grupo de empresas cujos serviços de AIA tendem a se simplificar com o passar do tempo, a empresa $\mathrm{C}$ argumentou que embora os EIAs, de forma geral, estejam se tornando mais complexos devido à dinâmica jurídica e a novas demandas advindas do processo de licenciamento, a empresa vem se especializando em atividades de monitoramento, como gerenciamento ambiental de obras, que se caracterizam como "procedimento", podem ser executadas por profissionais juniores e permitem previsões mais precisas de faturamento. A empresa $\mathrm{E}$ também citou que os estudos de licenciamento vêm se tornando mais complexos, necessitando de inovações devido ao surgimento contínuo de novas demandas, mas que atividades de acompanhamento ambiental vêm ganhando espaço dentro da organização. A empresa $\mathrm{F}$ citou que o acúmulo de experiência da equipe interna e a atuação em monitoramento ambiental justificam a tendência para uma carteira de projetos menos inovadora. Por fim, a empresa $\mathrm{H}$, além de justificar a evolução de sua classificação no contínuo pelo acúmulo de experiência de sua equipe, ressaltou que no setor sucroalcooleiro em que atua observa-se falta de interesse e participação pública nos processos de licenciamento.

\subsection{Práticas e ferramentas}

\subsubsection{Relativas à socialização}

A empresa A concordou total ou parcialmente com as questões 3.1, 3.2, 3.3 e 3.4, mencionando também que, apesar de não possuir sistema de gestão da qualidade certificado, os procedimentos internos determinam que reuniões de partida sejam realizadas no início de todos os projetos, para alinhamento das informações e definições das estratégias. Sua equipe de AlA está inserida em uma estrutura matricial composta por gerentes de células (energia e projetos lineares/ mineração) e gerentes temáticos (meios biótico, físico e socioeconômico). Os entrevistados consideram que essa estrutura facilita a transferência de conhecimento entre os profissionais. A empresa realiza "diálogos técnicos" para discutir conhecimentos gerados pelas experiências vivenciadas, sucessos e insucessos dos projetos, lições aprendidas e oportunidades de melhoria. Foi citado que embora a empresa considere essa prática relevante, a dinâmica dos projetos faz com que ela não ocorra com frequência satisfatória. Outra prática dessa organização é a rotação de profissionais trainee nas diversas atividades relativas à AlA, visando proporcionar-lhes uma visão integrada sobre a atuação da empresa. Quanto à circulação de profissionais em projetos de diferentes natureza, foi citado que essa prática ocorre esporadicamente de forma não planejada.

Dentre as empresas B, D e G, que opinaram que seus serviços de avaliação ambiental evoluem para situações complexas, apenas a empresa B concordou plena ou parcialmente com as questões sobre socialização. A empresa D mencionou que a designação de tutores ocorre somente em situações específicas e a empresa $\mathrm{G}$ citou que a troca de experiências e modelos conceituais através do trabalho em equipe não é satisfatória.

A empresa $B$ possui procedimentos internos que estabelecem reuniões de partida e acompanhamento 

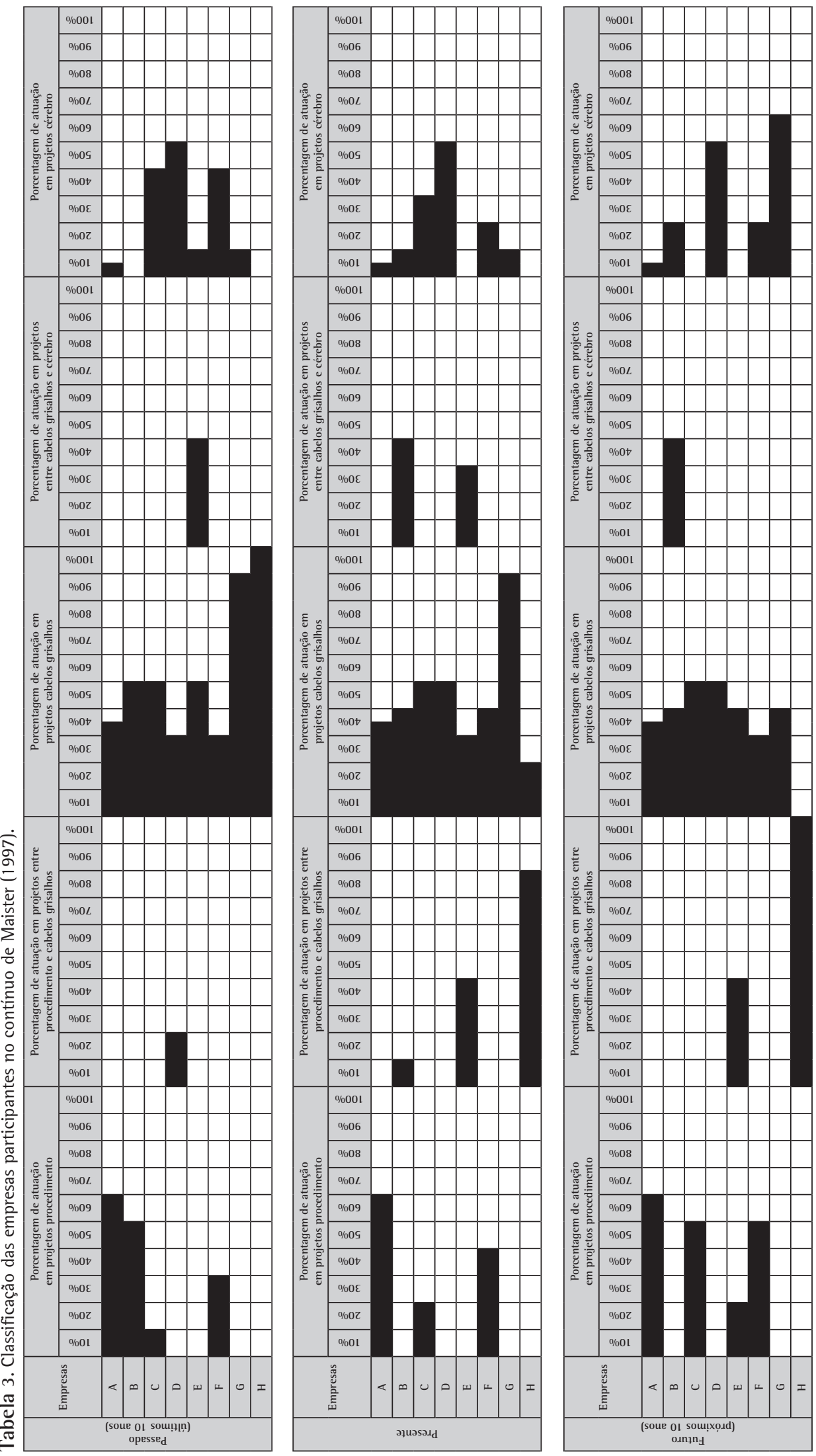
dos projetos e os entrevistados citaram que frequentemente realizam debates técnicos ou metodológicos, incluindo os diretores da empresa, para transferência de informações e conhecimentos aos menos experientes. A empresa possui apenas três patamares hierárquicos: diretores, coordenadores de projetos e técnicos e, segundo os entrevistados, não existem barreiras de comunicação entre eles. Mencionou-se que os coordenadores de projetos não se especializam em mercados específicos, desenvolvem competências para atuar em vários tipos de projetos.

A empresa D possui sistema de gestão de qualidade 1S0 9001:2008, que estabelece em seus procedimentos a necessidade de realização de reuniões de partida, acompanhamento e fechamento de projetos. Outra prática utilizada é a determinação de dois responsáveis por cada projeto, ou seja, o coordenador técnico é sempre tutorado por um superior. A estrutura hierárquica de seu departamento de AlA também é bastante plana, com dois gerentes aos quais subordina-se o corpo técnico. Para cada projeto designa-se um coordenador, segundo experiência e competência necessárias. A equipe relativamente enxuta (18 colaboradores), associada à atuação em grandes projetos em mercados diversificados faz com que atuem em diversas frentes. Sobre encontros internos com foco na equipe de $\mathrm{AlA}$, o representante da empresa D considera que essas ações ocorrem em frequência insuficiente; embora a empresa possua práticas institucionalizadas que incentivam essas atividades, mencionou-se que o ritmo de trabalho acaba por dificultar tais iniciativas.

Reuniões de partida de projetos também são prática estabelecida nos procedimentos internos da empresa G, que possui uma estrutura enxuta e plana, já que seu sócio diretor coordena os projetos de sua empresa, que conta com quatro profissionais de nível superior. A equipe interage constantemente, sendo que todos os técnicos participam de praticamente todos os projetos. Essa empresa não possui a cultura de realização de encontros ou conferências internas e o conhecimento se transfere preponderantemente pela convivência e prática.

No grupo das empresas que opinaram que seus serviços de avaliação ambiental evoluem para situações menos complexas (C, E, F e H), apenas a empresa F concordou plena ou parcialmente com as questões 3. A empresa $C$ mencionou que não realiza sessões de brainstorming, que a dinâmica do trabalho se faz sobre os textos produzidos e reuniões rápidas de alinhamento; ademais, às vezes não realiza reuniões de partida devido à rápida dinâmica dos projetos, ressaltando que o coordenador do projeto é responsável por disseminar as diretrizes para a equipe e que isso não se faz necessariamente por meio de reuniões. A estrutura física da empresa $\mathrm{C}$ permite que seus
74 colaboradores trabalhem no mesmo ambiente, facilitando assim o contato direto e a comunicação face a face, a estrutura hierárquica também é plana, dividida em dois níveis, diretoria e corpo técnico, os coordenadores de projetos são selecionados do corpo técnico em função de sua experiência e competências. Essa empresa possibilita a rotação de profissionais nos diferentes serviços de AlA executados, pois acredita que essa prática facilite o desenvolvimento de sua equipe e a melhoria de seus produtos. Um dos entrevistados mencionou:

Fizemos um erro estratégico no início, de separar as equipes. Quem só faz monitoramento, emburrece. Quem só faz EIA tende a se encantar com as palavras.

Essa prática é contrastante com a das demais empresas que também realizam serviços de acompanhamento dos projetos licenciados, já que todas mantêm equipes separadas.

A empresa E está em processo de criação de um procedimento que define a realização de pelo menos três reuniões de equipe no desenvolver dos ElAs: a primeira para difundir as características do empreendimento, a segunda para integrar o diagnóstico e a terceira para fechamento da análise dos impactos e proposição dos programas ambientais. 0 primeiro nível hierárquico da empresa E possui três diretorias, uma delas denominada diretoria técnica, cujo segundo nível hierárquico é composto por gerentes e o terceiro, pela equipe técnica. Tendo escritórios em duas localidades, foi mencionado que a cultura da empresa permite grande acessibilidade entre níveis hierárquicos e que as ferramentas de internet permitem contatos frequentes entre profissionais alocados em cidades distintas.

A empresa $F$, que também concordou com todas as questões propostas, tem dois níveis hierárquicos: diretoria e corpo técnico, e adota a prática de realização de encontros técnicos internos nos momentos de abertura e finalização dos ElAs.

A empresa $\mathrm{H}$ mencionou que as questões relativas à socialização não são pertinentes ao seu modelo de negócio, pois ela atua com equipe de consultores experientes em um mercado específico dentro de uma região específica. Foi alegado que esse cenário permite a consolidação satisfatória dos estudos sem a necessidade de realizar muitos encontros dos técnicos envolvidos. Note-se que essa é a menor empresa da amostra e que ela atua somente com um tipo de empreendimento.

\subsubsection{Relativas à externalização}

As empresas apresentaram posicionamentos muito similares relativos à externalização, um dos relatos obtidos representa as opiniões sobre essas questões: 
Creio que os próprios projetos desenvolvidos pelas empresas refletem a externalização, os projetos refletem de alguma forma o conhecimento tácito envolvido em seus processos de desenvolvimento.

Em relação às questões 3.5, 3.14 e 4.4, apenas a empresa D possui sistema de gestão da qualidade certificado 1S0 9001:2008 e histórico de listas de discussão eletrônicas; as empresas A, D e E possuem intranet. A existência de sistema de qualidade foi proposta como questão suplementar, pois esse tipo de sistema deve apresentar traços da cultura empresarial, principalmente através da missão das empresas e sua política. Considerando a premissa de que a cultura das empresas faz parte do conhecimento tácito das organizações, lembrando que Walsh \& Ungson (1991) a descreveram como um repositório de conhecimento, tem-se então que a representação de seus traços pode ser considerada como um processo de externalização. Salienta-se que todas as empresas participantes possuem missão e visão difundidas.

\subsubsection{Relativas à combinação}

Todas as empresas, exceto a G, possuem o histórico de seus projetos classificados por ano de execução ou clientes, mas não possuem sistemas de busca por assunto ou tópicos como localização geográfica. Apenas a empresa D apresentou uma ferramenta, em sua intranet, capaz de pesquisar temas técnicos desenvolvidos ou pesquisados internamente, ferramenta que também possibilita identificar técnicos em função de suas competências e áreas de interesse, abrangendo seus escritórios localizados em diversos países. As empresas D e F possuem sistemas próprios de gestão de projetos capazes de organizar o histórico das atividades neles desenvolvidas, assim como as horas despendidas pelos técnicos na realização de atividades. Em relação à existência de sistema de informação que auxiliem a pesquisa de consultores especialistas externos, apenas as empresas C e D confirmaram a utilização dessa ferramenta, sendo que as demais utilizam redes de relacionamento informais para identificar esses especialistas.

\subsubsection{Relativas à internalização}

Todas as empresas concordaram que seus projetos oferecem oportunidades de aprendizagem a seus técnicos. Para o desenvolvimento de um ElA é necessário ler e interpretar grandes quantidades de informação, proporcionando assim situações adequadas para internalização. Em relação aos planos de desenvolvimento profissional com participação dos colaboradores, as empresas A, B, D, E e F confirmaram essa prática.

\subsection{Repositórios de conhecimento}

As empresas A, B, C, D, F e $\mathrm{H}$ relataram que os colaboradores sabem quem detem determinadas informações e conhecimentos e que suas equipes sabem onde a informação deve ser armazenada para ser reutilizada no futuro. As empresas E e G descreveram que suas equipes ainda cometem erros na estocagem de informações nas bases internas.

Em relação à afirmação "Os estudos desenvolvidos pela empresa possuem particularidades tão específicas que é muito raro encontrar informações necessárias em banco de dados internos", a empresa $\mathrm{H}$ foi a única que discordou totalmente dela. Observe-se que essa é a empresa que trabalha com um único tipo de projeto.

0 Tabela 4 apresenta a classificação, por ordem de importância, atribuída pelos entrevistados aos repositórios de conhecimento de sua empresa. Nota-se que apenas a empresa D não classificou seus colaboradores em primeiro lugar, apontando a cultura organizacional como mais relevante. A empresa $\mathrm{F}$ foi a única que citou, espontaneamente, os clientes como um repositório de conhecimento.

Tabela 4. Classificação da importância dos repositórios de conhecimento.

\begin{tabular}{|c|c|c|c|c|c|c|c|c|c|}
\hline \multirow{2}{*}{$\begin{array}{l}\text { Repositórios de } \\
\text { conhecimento }\end{array}$} & \multicolumn{8}{|c|}{ Empresas } & \multirow{2}{*}{$\begin{array}{c}\text { Classificação mais } \\
\text { frequente }\end{array}$} \\
\hline & A & B & $\mathrm{C}$ & $\mathrm{D}$ & $E$ & $\mathrm{~F}$ & G & $\mathrm{H}$ & \\
\hline Bases de dados internas & 3 & 5 & 3 & 3 & 2 & 3 & 2 & 3 & 3 \\
\hline Bases de dados externas & 5 & 2 & 3 & 5 & 3 & 2 & 3 & 2 & 2 e 3 \\
\hline Cultura organizacional & 2 & 3 & 4 & 1 & 5 & 1 & 4 & 6 & $1 \mathrm{e} 4$ \\
\hline Redes sociais externas & 4 & 4 & 6 & 4 & 6 & 4 & 1 & 1 & 4 \\
\hline Colaboradores & 1 & 1 & 1 & 2 & 1 & 1 & 1 & 1 & 1 \\
\hline $\begin{array}{l}\text { Listas de discussão eletrônicas } \\
\text { internas para resolução de problemas }\end{array}$ & 7 & 7 & 7 & 6 & 7 & 7 & 5 & 5 & 7 \\
\hline $\begin{array}{l}\text { Centros de conhecimento } \\
\text { (universidades e grupos de pesquisa) }\end{array}$ & 6 & 6 & 5 & 7 & 4 & 2 & 3 & 4 & 4 e 6 \\
\hline Clientes & & & & & & 5 & & & 5 \\
\hline
\end{tabular}




\subsection{A prática da avaliação de impacto ambiental de projetos}

Dentre as questões relacionadas diretamente à elaboração de ElAs e outros estudos ambientais para licenciamento, a maioria delas serviu para verificar se as empresas reconhecem a aprendizagem organizacional decorrente do relacionamento com as comunidades impactadas, clientes e órgãos ambientais.

As empresas A, D, F e G consideram que a aprendizagem se faz em ciclos simples. As empresas B e E consideram que ocorrem ciclos simples e duplos durante os relacionamentos citados. A empresa C considera que ocorrem ciclos simples com as comunidades e clientes e ciclos simples e duplos com os órgãos ambientais. A empresa $\mathrm{H}$ considera que mesmo a aprendizagem em ciclo simples ocorre raramente.

As empresas A, B, C, F, G e H consideram que a troca de informação e contatos face a face entre os consultores especialistas externos e a equipe técnica interna é no mínimo razoável. Um dos entrevistados relatou: "Os consultores especialistas que trabalham conosco são uma extensão do conhecimento técnico de nossa equipe e uma excelente fonte de aprendizado." As empresas D e E relataram dificuldades de comunicação entre equipe interna e consultores especialistas externos.

\section{Discussão}

Observou-se que a prática de AlA abrange uma gama de projetos que podem ser classificados desde “procedimento" a "cérebro". As empresas pesquisadas posicionam diferentemente sua carteira de projetos ao longo do contínuo de Maister (1997), conforme suas estratégias de mercado e competências. As respostas às perguntas do grupo 5 não sugerem uma correlação entre o contínuo de Maister e os ciclos de aprendizagem de Argyris \& Schön (1996), mas constatou-se que o ambiente externo é reconhecido como um fator importante na aprendizagem organizacional.

Considerando que o alinhamento ao ambiente é relevante na aprendizagem organizacional (Fiol \& Lyles, 1985), conclui-se que as práticas de GC são relacionadas à diversificação de atuação no mercado e de localização dos projetos (Figura 9), ou seja, quanto maior a diversificação, maior tende a ser a complexidade do ambiente externo, o que implica maior necessidade de socialização entre os técnicos para resolução dos problemas. As empresas que atuam no quadrante 1 tendem a se habituar a contextos ambientais semelhantes, empreendimentos similares e interagem com os mesmos órgãos ambientais.

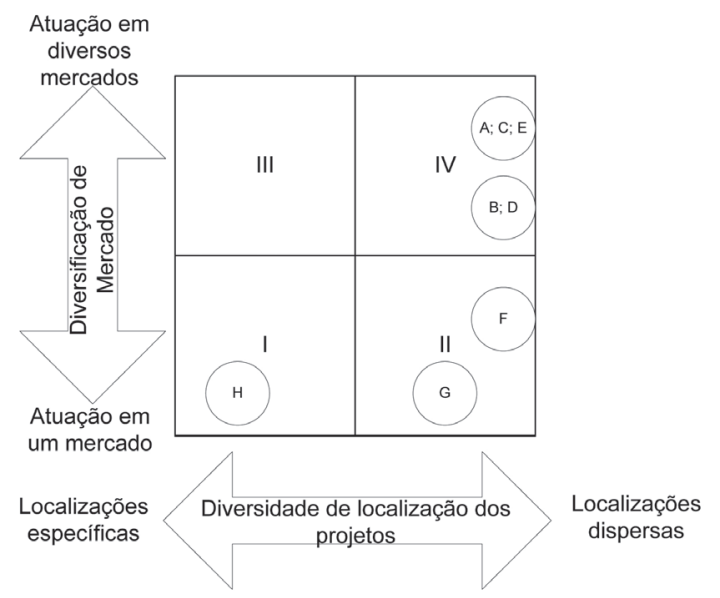

Figura 9. Práticas de GC em função da diversidade de mercado e localização dos projetos.

Com o passar do tempo e acúmulo de experiência, a necessidade de socialização para a resolução de problemas tende a diminuir e os projetos tendem a se situar entre "cabelos grisalhos" e "procedimento". No segundo quadrante, mesmo que, com o passar do tempo, as consultorias passem a conhecer bem a natureza dos empreendimentos, a diversidade de localização dos projetos faz com que a análise da relação projeto/ambiente seja complexa; ademais, os consultores que atuam nesse quadrante se relacionam com diversos órgãos ambientais e com os respectivos arcabouços legais. A atuação no quadrante 111 apresenta situações opostas ao quadrante II, ou seja, maior conhecimento do meio ambiente e menor conhecimento das interferências no meio. 0 fato de nenhuma empresa se posicionar nesse quadrante provavelmente indica que quando passam a atuar em diversos mercados os projetos dos clientes estão localizados em diferentes partes do território nacional, ou mesmo no exterior, levando-as ao quadrante IV. Considera-se que nos quadrantes $11 \mathrm{e}$ 111 haja necessidade moderada de socialização para resolução de problemas. As empresas atuantes no quadrante IV estão constantemente encarando novas situações, fato que, associado à interdisciplinaridade demandada para desenvolvimento de EIAs, resulta na necessidade de constante socialização. Cabe salientar que o posicionamento na matriz proposta não tem relação com a qualidade dos serviços prestados.

A pesquisa mostrou que, mesmo sem adotar explicitamente políticas ou iniciativas formais de GC, as empresas utilizam várias ferramentas e práticas mencionadas na literatura ou recomendadas (Tabela 5). Sete empresas apresentam práticas similares e culturas que incentivam o processo de socialização, o que pode estar relacionado ao fato de que essas empresas possuem atualmente, mesmo que em diferentes 


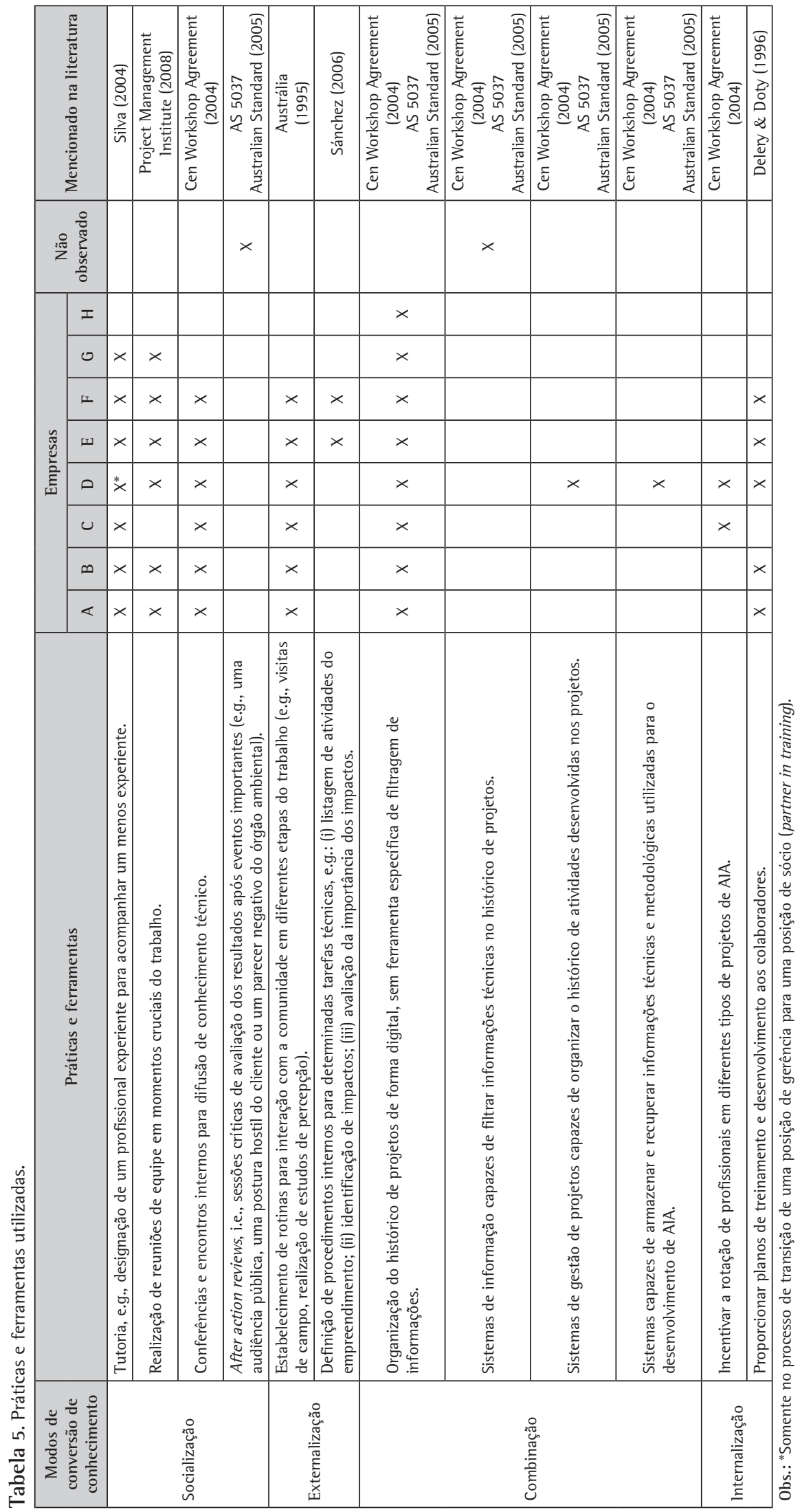


proporções, projetos entre "cérebro" e "cabelos grisalhos”. Notaram-se diferenças expressivas apenas entre a empresa $\mathrm{H}$ e as demais.

Quanto aos repositórios de conhecimento, é sugerido que a classificação dos colaboradores como os mais relevantes repositórios de conhecimento pode servir de explicação para a constatação de que os maiores esforços das empresas pesquisadas, com exceção da empresa $\mathrm{H}$, são relativos à socialização. Nota-se também que as empresas $\mathrm{G}$ e $\mathrm{H}$ classificaram as redes sociais externas (que englobam consultores externos), juntamente com os colaboradores, na primeira posição, possivelmente porque suas equipes internas são reduzidas (Tabela 2).

A proposição de que as organizações enfatizam o uso de redes de relacionamento ou bancos de dados eletrônicos conforme suas estratégias de mercado (Hansen et al., 1999) foi observada ao comparar-se a empresa $\mathrm{H}$ com as demais. Verificou-se que a empresa $\mathrm{H}$ lida majoritariamente com situações nas quais a incerteza pode ser reduzida por aumento de informação, uma vez que, além de possuir grande experiência acumulada em um setor específico, não atua em projetos complexos com participação efetiva da sociedade no licenciamento. As demais empresas - mesmo possuindo participações em projetos "cérebro" em proporções distintas - enfrentam situações ambíguas nas quais o aumento da quantidade de informação não resolve os conflitos, necessitando soluções criadas em conjunto, consequentemente, preocupam-se com práticas que estimulem a socialização.

\section{Conclusões}

0 conhecimento é um dos principais ativos de uma empresa de consultoria ambiental, de modo que sua retenção e transferência são estratégicas. A pesquisa indica que as necessidades de $\mathrm{GC}$ no ramo estudado dependem do nicho de mercado, diversidade de localização e tipos de projeto em que atuam as empresas: quanto mais diversa é a empresa e quanto maior o peso dos ElAs em sua carteira, maiores serão suas necessidades de empregar práticas e ferramentas que incentivem a transferência de conhecimentos tácitos para tácitos (socialização). Quanto menos diversa é sua atuação, maior a probabilidade de resolução de problemas de forma individual, recuperando informações através de bancos de dados.

Não foi possível correlacionar-se a posição das empresas no contínuo de Maister com as práticas e ferramentas de GC, nem com as experiências relacionadas à criação, troca e retenção de conhecimento. Porém, quando se analisa somente o posicionamento atual das empresas no contínuo, percebe-se que as sete empresas que apresentaram práticas e ferramentas semelhantes possuem projetos "cérebro" ou entre "cérebro" e "cabelos grisalhos", mesmo que em diferentes proporções.

As relações entre o posicionamento no contínuo de Maister (1997) e os repositórios de conhecimento também foram observadas de forma parcial. Notou-se que todas as empresas qualificaram os colaboradores em primeiro ou segundo lugar na classificação dos repositórios de conhecimento, porém uma delas acessa preponderantemente o conhecimento explícito advindo dos colaboradores por seus produtos técnicos, enquanto as demais empresas acessam também os conhecimentos tácitos através da socialização. Nesse contexto observou-se que as relações informais dos consultores para a troca de conhecimento ocorrem com menos frequência nessa empresa em relação às demais. Clientes, centros externos e listas de discussão foram os possíveis repositórios de conhecimento classificados como os menos importantes pelos entrevistados. As empresas de consultoria que atuam no ramo de AIA, representadas aqui por oito empresas, adotam diversas ferramentas e práticas de $\mathrm{GC}$, mas não o fazem de maneira sistemática, nem mediante estratégias explícitas. Práticas de socialização do conhecimento, como tutoria, reuniões de equipe e encontros técnicos internos são usadas pela maioria das consultorias, mas nenhuma delas realiza uma avaliação crítica ao término de cada projeto (after action review) que possibilite captar de modo sistemático as lições aprendidas. Definição de rotinas e procedimentos de trabalho que auxiliem a transformação de conhecimento tácito em explícito são pouco utilizadas por essas empresas, assim como métodos de combinação do conhecimento detido pela organização.

Algumas empresas estudadas reconhecem a necessidade de aprimorar práticas de GC, mas não têm alocado recursos suficientes para tal. Foi constatado que há um campo propício para sistematização das práticas já adotadas e introdução de novas ferramentas. Acredita-se que um estudo de caso para aprofundar o conhecimento da eficiência e eficácia das práticas já adotadas, assim como analisar a pertinência da introdução de novas ferramentas complementem os resultados aqui apresentados.

\section{Referências}

André, P., Delisle, C. E., \& Reverét, J. P. (2003). Évaluation des impacts sur l'environnement. Processus: Acteurs et pratique pour un développement durable (2nd ed.). Presses Internationales Polytechnique, École Polytechnique de Montréal. 
Antonello, C. S. (2005). A metamorfose da aprendizagem organizacional: uma revisão crítica. In: R. Ruas, C. Antonello \& Boff L. (Ed.), Aprendizagem organizacional e competências (pp. 12-33). Porto Alegre: Artmed.

Argyris, C., \& Schön, D. (1996). Organizational Learning 11 - Theory, Method and Practice. Adyson-Wesley Publishing Company.

Australian Standard. (2005). AS 5037: Knowledge Management - a guide. AS.

Austrália. Environmental Protection Agency - EPA. (1995). Community Consultation and Involvement. Barton: Best Practice Environmental Management in Mining.

Bond, A., Viegas, C. V., Coelho, C. C. S. R., \& Selig, P. M. (2010). Informal knowledge processes: the underpinning for sustainability outcomes in EIA? Journal of Cleaner Production, 18, 6-13. http://dx.doi.org/10.1016/j. jclepro.2009.09.002

Cen Workshop Agreement. (2004). European Guide to Good Practice in Knowledge Management - Part 1: Knowledge Management Framework.

Child, J. T., \& Shumate, M. (2007). The Impact of Communal Knowledge Repositories and People-Based Knowledge Management on Perceptions of Team Effectiveness. Management Communication Quarterly, 21, 29-54. http://dx.doi.org/10.1177/0893318907301987

Cook, S. D. N., \& Yanow, D. (1993). Culture and Organizational Learning. Journal of Management Inquiry, 2(4).

Crossan, M. M., Lane, H. W., \& White, R. E. (1999). An organizational learning framework: from intuition to institution. The Academy of Management Review, 24(3), 522-37.

Daft, R. L., \& Lengel, R. H. (1986). Organizational information requirements, media richness and structural design. Management Science, 32(5), 554-571. http://dx.doi. org/10.1287/mnsc.32.5.554

Delery, J. E., Doty, H. D. (1996). Modes of Theorizing in Strategic Human Resource Management: Tests of Universalistic, Contingency and Configurational Performance Predictions. Academy of Management Journal, 39(4), 802-835. http:// dx.doi.org/10.2307/256713

Easterby-Smith, M., Crossan, M. M., \& Nicolini, D. (2000). Organization learning: debates past, present and future. Journal of Management Studies, 37(6), 783-796. http:// dx.doi.org/10.1111/1467-6486.00203

Eisenhardt, K. (1989). Building Theories from Case Study Research. Academy of Management Review, 14(4), 532550.

Fiol, C. M., \& Lyles, M. A. (1985). Organizational Learning. Academy of Management Review, 10(4), 803-813.

Fitzpatrick, P. (2006). In it Together: Organizational Learning Through Participation in Environmental Assessment. Journal of Environmental Assessment Policy and Management, 8, 157-182. http://dx.doi.org/10.1142/ S1464333206002463

Galbraith, J. R. (1973). Designing complex organizations. Reading: Addison-Wesley Publishing Company.

Hanisch, B., Lindner, F., Mueller, A., \& Wald, A. (2009). Knowledge Management in Project Environments. Journal of Knowledge Management, 13(4), 148-160. http://dx.doi.org/10.1108/13673270910971897
Hansen, M. T., Nohria, N., \& Tierney, T. (1999). What's your strategy for managing knowledge? Harvard Business Review, 77(2), 106-166.

Käpylä, J., Laihonen, H., Lönnqvist, A., \& Carlucci, D. (2011). Knowledge-intensity as an organizational characteristic. Knowledge Management Research \& Practice, 9, 315326. http://dx.doi.org/10.1057/kmrp.2011.23

Lethbridge, T. C. (1998). Metrics for concept-oriented knowledge bases International. Journal of Software Engineering and Knowledge Engineering, 8(2), 161-188. http://dx.doi.org/10.1142/S021819409800011X

Maister, D. H. (1997). Managing the Professional Service Firm. New York: Free Press.

Miguel, P. A. C. (2007). Estudo de Caso na engenharia de produção: estruturação e recomendações para sua condução. Produção, 17(1), 216-229. http://dx.doi. org/10.1590/S0103-65132007000100015

Nakano, D. N. (2002). Gestão de Conhecimento e Serviços Profissionais: Um Estudo em Empresas de Consultoria (Tese de doutorado). Escola Politécnica da USP, Universidade de São Paulo, São Paulo.

Nakano, D. N., \& Fleury, A. C. C. (2005). Utilizando estoques de conhecimento organizacional: um quadro de referência. Revista de Administração, 4O(2), 136-144.

Nonaka, 1., \& Takeuchi, H. (1995). The Knowledge-creating company: how Japanese companies create the dynamics of innovation. New York: Oxford University Press.

Olivera, F. (2000). Memory systems in organizations: an empirical investigation of mechanisms for knowledge collection, storage and access. Journal of Management Studies, 37(6), 811-832. http://dx.doi.org/10.1111/14676486.00205

Oltra, V. (2003). Sistemas de Recursos Humanos de Alto Compromiso, Aprendizaje Organizativo y Gestión del Conocimiento: hacia un modelo integrador. Arxius de Ciencies Sociales, 9.

Pawlowsky, P. (2001). The Treatment of organizational learning in management science. In: M. Dierkes, A. Berthoin Antal, J. Child \& 1. Nonaka (Eds.), Handbook of organizational learning \& knowledge (pp. 61-88). New York: Oxford.

Project Management Institute - PMl. (2008). Project Management Body of Knowledge. PMl.

Rueschemeyer, D. (1983). Professional autonomy and the social control of expertise. In: R. Dingwall \& P. Lewis (Ed.), The Sociology of Professions. London: Macmillan.

Sabbag, P. Y. (2007). Espirais do Conhecimento: Ativando indivíduos, grupos e organizações. São Paulo: Editora Saraiva.

Sánchez, L. E. (2006). Avaliação de Impactos Ambientais: Conceitos e Métodos. São Paulo: Oficina dos Textos.

Sánchez, L. E. (2010). Avaliação de impacto ambiental e seu papel na gestão de empreendimentos. In: Vilela Junior, A., Demajorovic, J. (Ed.). Modelos e Ferramentas de Gestão Ambiental: Desafios e Perspectivas para as Organizações (2. ed., pp. 83-114). São Paulo: Senac.

Sánchez, L. E., \& Morrison-Saunders, A. (2011). Learning about knowledge management for improving impact assessment in a government agency: The Western Australian experience. Journal of Environmental Management, 92, 2260-2271. http://dx.doi.org/10.1016/j.jenvman.2011.04.010 
Schulz, M. (2001). The uncertain relevance of newness: organization learning and knowledge flows. Academy of Management Journal, 44(4), 661-681. http://dx.doi. $\operatorname{org} / 10.2307 / 3069409$

Silva, S. L. (2004). Gestão do Conhecimento: uma revisão crítica orientada pela abordagem da criação do conhecimento. Ciência da Informação, 33(2), 143-151. http://dx.doi.org/10.1590/S0100-19652004000200015

Sinclair, A. J., Diduck, A., \& Fitzpatrick, P. (2008). Conceptualizing learning for sustainability through environmental assessment: critical reflections on 15 years of research. Environmental Impact Assessment Review, 28, 415-428. http://dx.doi.org/10.1016/j.eiar.2007.11.001

Slack, N., Chambers, S., Harland, C., Harrison, A., \& Johnston, R. (1997). Administração da Produção. São Paulo: Atlas.
Starbuck, W. (1992). Learning by knowledge intensive firms. Journal of Management Studies, 29, 713-740. http:// dx.doi.org/10.1111/j.1467-6486.1992.tb00686.x

Taminiau, Y., Smit, W., \& De Lange, A. (2009). Innovation in management consulting firms through informal knowledge sharing. Journal of Knowledge Management, 13(1), 4255. http://dx.doi.org/10.1108/13673270910931152

Voss, C., Tsikiriktsis, N., \& Frohlich, M. (2002). Case Research in Operations Management. International Journal of Operations Management, 22(2), 195-219. http://dx.doi. org/10.1108/01443570210414329

Walsh, J. P., \& Ungson, G. R. (1991). Organization Memory. The Academy of Management Review, 16(1), 57-91.

Yin, R. K. (2001). Estudo de Caso: Planejamento e método (2. ed.). São Paulo: Bookman.

\title{
Knowledge management in environmental consulting firms
}

\begin{abstract}
In this study, the managers of eight consulting companies established in Brazil were interviewed to explore knowledge management and the practices adopted by environmental consulting companies specializing in environmental impact assessment. The study sought to verify the existence of a relationship between the degree of complexity and innovation of a company's project portfolio, along with (i) knowledge management practices and tools mentioned in the literature; (ii) knowledge repositories used by consulting companies; and (iii) their experiences related to knowledge creation, exchange and retention. It was found that knowledge socialization practices were employed by most consultancies, but post-action reviews were not conducted to identify lessons learned. Routines and procedures capable of transforming tacit knowledge into explicit knowledge were not widespread, while knowledge combination practices experienced restricted utilization. The study concluded that the most appropriate knowledge management tools may depend on how diversified such organizations are in terms of both markets and localization.
\end{abstract}

\section{Keywords}

Knowledge management. Environmental consulting. Knowledge repositories. Environmental impact assessment. 